INVESTIGACIÓN/RESEARCH

\title{
EL CARTEL EN EL “REALISMO SOCIAL” DEL CINE ESPAÑOL
}

Tamara Bueno Doral1: Universidad Complutense de Madrid. España trbueno@pdi.ucm.es

Noelia García Castillo²: Universidad Complutense de Madrid. España noeliagcastillo@gmail.com

\section{RESUMEN}

El neorrealismo italiano supuso, entre otras cosas, una nueva estética cinematográfica que, expresándose de diversas formas según las características nacionales, tuvo una enorme importancia en distintos países del continente europeo durante la posguerra de la Segunda Guerra Mundial. En el caso español, resulta evidente el influjo que ejerció este movimiento sobre algunos directores en las décadas de los años cincuenta y sesenta. Asimismo, en numerosas ocasiones la corriente neorrealista transgredió la pantalla para transmitirse a los carteles cinematográficos que anunciaban sus películas. En el presente artículo se pretende demostrar la inexistencia en el ámbito español de un diseño de cartelería que aportara una estética diferenciada y propia, en contraposición a lo que sí se produjo en el caso italiano. Con este fin, presentamos las conclusiones alcanzadas tras aplicar un riguroso análisis de contenido que contemplaba el significante icónico y el textual. Por otro lado, en la comunicación se muestra cómo, a pesar de las múltiples dificultades a las que se enfrentaban los cartelistas (especialmente la censura y la falta de libertad creativa imperantes en la época), algunos de ellos alcanzaron un gran nivel creativo, consiguiendo aportar interesantes innovaciones al arte publicitario.

PALABRAS CLAVE: Realismo social - Cartel cinematográfico - Cine español - Historia del cine - Neorrealismo

\footnotetext{
${ }^{1}$ Autor Correspondiente:

Tamara Bueno Doral: Profesora e investigadora. Facultad de Ciencias de la Información de la Universidad Complutense de Madrid. España.

Correo: trbueno@pdi.ucm.es

${ }^{2}$ Noelia García Castillo: Becaria del Programa FPU del Ministerio de Educación. Universidad Complutense de Madrid. España.

Correo: noeliagcastillo@gmail.com
} 


\title{
FILM POSTER IN THE “SOCIAL REALISM” OF SPANISH CINEMA
}

\begin{abstract}
Italian neorealism entailed, among other things, a new cinematographic aesthetics which, expressed in diverse forms depending on national characteristics, had a paramount importance in different countries all over post-Second World War Europe. In the case of Spain, this movement obviously influenced several directors in the fifties and sixties. Likewise, the neorealist stream transgressed the limits of the screen to spread to film posters in numerous occasions. In the present research paper, we intend to discuss the non-existence in Spain of a poster design which contributed to a distinct aesthetics, in contrast with the phenomenon occurred in Italy. For this purpose, we introduce the results achieved after applying a rigorous content analysis that combined both iconic and textual signifiers. Furthermore, this paper shows how a few Spanish poster designers reached high creative standards that provided interesting innovations to the advertising art, in spite of the multiple adversities they had to face, such as the censorship and lack of artistic freedom prevailing during this period.
\end{abstract}

KEY WORDS: Social realism - Film poster - Spanish cinema - History of film Neorealism

\section{INTRODUCCIÓN}

La interrogante inicial que provoca la realización de este trabajo es si la existencia del llamado "realismo social" en el cine español, directamente influenciado por el Neorrealismo italiano, fue capaz de producir una cartelería cinematográfica específica desde el punto de vista estilístico.

Nuestra hipótesis es que en el ámbito español no hay diferencias significativas entre el cartel del "realismo social" y el cartel de cinematográfico español en general, y si, excepcionalmente se producen innovaciones, son las introducidas por la iniciativa personal de los cartelistas de cine españoles.

\section{METODOLOGÍA}

En una primera fase, la metodología empleada ha consistido en realizar una lectura flotante, que da lugar a que dispusiéramos de las primeras impresiones acerca del objeto de estudio, previamente a la fase analítica. La lectura flotante ratificó la selección de la muestra, permitiéndonos descartar otras posibles.

En segundo lugar, partiendo de las conclusiones alcanzadas en la fase anterior, hemos efectuado un análisis de contenido aplicado al cartel del cine español de "realismo 
social".

\subsection{Muestra seleccionada}

La muestra tiene dos partes claramente diferenciadas: una primera de 47 carteles de cine español, realizados desde los años 10 hasta la década de los sesenta inclusive del siglo XX, coincidiendo con el final del llamado cine de "realismo social", y cuya intención es mostrar la evolución del cartel cinematográfico en nuestro país y así, poder extraer conclusiones acerca del modelo de cartel de cine al que se someten, por las razones que explicaremos más adelante, los cartelistas españoles.

La necesidad de esta parte "no específica" de la muestra viene justificada porque nos permite, siguiendo los criterios metodológicos enunciados, realizar un estudio comparativo entre ésta y la correspondiente al cartel del cine español de "realismo social" desde los antecedentes hasta el final de este movimiento cinematográfico.

Con este objetivo hemos examinado, en segundo lugar, 39 carteles pertenecientes al cine del "realismo social", extrayendo las semejanzas y diferencias existentes entre ambos grupos de carteles.

En total, el universo de referencia está constituido por una muestra de 86 carteles de cine español, aparecidos desde 1915 hasta la década de los sesenta.

\subsection{Análisis de contenido}

El análisis de contenido que hemos aplicado a la muestra se divide en tres partes:

- Análisis formal: Título, autor, edición, lugar, editor, año, descripción física, estado de conservación, notas e ISBD.

- Análisis de contenido: texto (firma del cartelista, eslogan, etc.) e imagen (distintos descriptores, logotipo, etc.)

- Ficha de la película: año, directores, intérpretes, etc.

Las partes examinadas en ambos grupos de la muestra han sido específicamente empleadas en otras investigaciones sobre el cartel cinematográfico español (Fernández Mellado, 2007). Por otro lado, hemos tenido en cuenta también tres constituyentes: el significante icónico (imagen), el significante lingüístico (texto), y el significante compuesto (Bonhomme, 2000).

\section{ANÁLISIS Y DISCUSIÓN}

\subsection{Los primeros pasos del cartel de cine en España}

La relación entre cartel y cine, ha sido larga y fructífera, remontándose incluso a las producciones precinematográficas, como es el caso de Pantomimes Lumineuses, 
Théatre Optique, obra de Emyle Reynaud y diseño del considerado "padre del cartel publicitario moderno": Jules Chéret (Gutiérrez Espada, 1998).

El cartel cinematográfico es un medio prolífico con vocación popular en el que se conjugan las manifestaciones artísticas de los autores y su finalidad puramente comercial. Así, la libertad creativa de los cartelistas estará la mayoría de las veces limitada a este objetivo, por lo que "vender" el producto va a determinar la composición de mensajes claros, sencillos e inteligibles, por encima de otras consideraciones. Numerosos autores coinciden en señalar la importancia del valor artístico y estético del cartel, denominándolo incluso "publicidad artística", mientras que otros afirman que "el cartel únicamente es un medio, un vehículo de comunicación, o mejor dicho, de información entre el comerciante y el público" (Barnicoat, 1976).

La incorporación del cartel de cine en España fue tardía, aun cuando el cine llegó tempranamente (1896), y cuando ya existía un amplio desarrollo del cartel tipográfico. No obstante, el nuevo medio gozará de un extenso apoyo popular y consideración social, como se deduce de la información aparecida en 1902 el semanario Blanco y Negro:

Los carteles como manifestación democrática y popular, sirven de indicador de la cultura nacional y contribuyen a educar el gusto y a dirigir las aficiones del pueblo. Esos carteles, lejos de afear las paredes y ensuciar los edificios, llegan a hacer de éstos verdaderos museos al aire libre. Sus artífices son los dibujantes y coloristas de gran imaginación, rara vez los pintores de casta, ya que esta clase de obras poco o nada tienen en común con la composición, el colorido y el dibujo de los cuadros al óleo (García Fernández, 1985).

La cita nos muestra además que, al inicio, los creadores de los carteles en España estaban claramente diferenciados de los artistas, al contrario de lo que sucedía en algunos países europeos, como en Francia, cuna del cartel publicitario moderno. Sin embargo, encontramos artistas españoles que se dedican también al cartel de cine, como por ejemplo, el pintor catalán Antoni Clavé, quien integró con gran acierto los recursos de las vanguardias con las imágenes y argumentos de las películas. Por otro lado, debemos señalar que en España los llamados "dibujantes y coloristas", sólo alcanzarían la categoría de ilustradores años después, gracias en parte al amplio número de cartelistas de gran nivel que se fueron incorporando desde el primer cuarto de siglo hasta la época dorada de los años 30 (Rafael de Penagos, Salvador Bartolozzi, César Fernández Ardavín, Federico Ribas, Félix Alonso, etc.).

Por lo tanto, durante los años veinte se irán consolidando las bases de lo que posteriormente será el cartel cinematográfico en España:

En los inicios predomina un estilo clásico, con composiciones de factura pictoricista y tratamientos formalmente muy conservadores. Pero a partir de los años 20 se produce la asimilación paulatina de elementos de las 
vanguardias históricas (...), el abandono de la perspectiva tradicional en beneficio del uso de la técnica plana y la influencia de la propia técnica cinematográfica (Tranche, 2005).

Ya apreciamos entonces que los autores de carteles cinematográficos no disponían de la libertad creativa que desarrollaban en el cartel comercial. El resultado son diseños muy encorsetados y poco imaginativos, en los que el contenido se limita a la reproducción de una escena, o varias, de la película y/o la representación de los protagonistas del film (en menor medida). Así, en una encuesta publicada en el número 82 de la revista "Popular film" en 1928 (Baena, 2005), titulada "encuesta a nuestros dibujantes", los autores afirman no disponer de la libertad necesaria para sus creaciones puesto que las exigencias que les imponían las distribuidoras cinematográficas, se limitaban a trasladar al cartel imágenes a partir de una fotografía determinada de la película en cuestión. No obstante, a pesar de las rígidas reglas a las que se tenían que ceñir, existieron cartelistas que consiguieron un gran nivel creativo, un liberalismo artístico "que no tuvo parangón en ninguna otra etapa del cartelismo cinematográfico español" (Baena, 2005). Podemos afirmar por tanto que el cartel cinematográfico español de los años veinte alcanzó el mayor esplendor artístico de su historia.

Desde la década de los 30, se aprovecha ampliamente el star-system español que había desarrollado CIFESA (distribuidora desde 1932 y productora desde 1934), con carteles de colores chillones generalmente, en los que se emplea el realismo al servicio de la estrella, a partir de un retrato de la misma, o fotomontajes sencillos. Este modelo se mantuvo también en la posguerra: "reclamos en los que predominan diseños mediante las efigies de las estrellas, que explotan un estilo claroscurista y de fuertes entintados [...]" (Sánchez López, 1997). Así, las reglas que se siguen en la realización de los anuncios cinematográficos, tienen como resultado una representación del protagonista o protagonistas del film, acompañada en ocasiones de una pequeña escenificación de las acciones argumentales o temáticas. En líneas generales, a partir de los años treinta, el cartel pierde la creatividad y la imaginación con que se presentaba en la década anterior, a excepción de aquéllos realizados por el cartelista Josep Renau, al que recordaremos más adelante, puesto que también diseñó algunos carteles para películas pertenecientes al "realismo social".

En conclusión, podemos afirmar que durante los primeros años de desarrollo del cartel en nuestro país, exceptuando el liberalismo artístico que se produjo en los años veinte, el cartel encuentra en el propio espectáculo cinematográfico su máximo referente. Los cartelistas deben atenerse a unas rígidas reglas de composición que se acentúan con el transcurso de los años y el uso extendido del propio medio.

\subsection{El cine español de realismo social}

El Neorrealismo es un movimiento cinematográfico de posguerra que, aunque surge en Italia, supondrá un modelo que siguen otros países europeos, adaptándolo a sus 
propias características nacionales. En síntesis, se caracteriza por tramas ambientadas en los sectores más desfavorecidos de la sociedad, abundante empleo de exteriores para los rodajes (dada la escasez de medios que había en Europa después de la II Guerra Mundial) y, principalmente, por su clara intención de mostrar la realidad:

El Neorrealismo no nació por generación espontánea. En pleno fascismo se han dejado oír las voces de los jóvenes que estudian en el Centro Experimentale y de algunos maestros reclamando un retorno a la realidad que la censura oficial prohíbe. Se pide del cine que sea, como el famoso espejo de Stendhal, un reflejo exacto de la realidad (Gubern, 1982)

Resulta evidente la influencia que ejerció el cine neorrealista italiano sobre algunos directores españoles en las décadas de los años cincuenta y sesenta. Durante los años previos a las Conversaciones de Salamanca (1955), en las que se afirma la necesidad de sustituir los contenidos patrióticos y folclóricos por un cine más crítico que muestre los problemas de la sociedad, nos encontramos con la considerada por muchos como la primera película del neorrealismo español: "Surcos", dirigida por Nieves Conde. La influencia del cine neorrealista italiano en el cine español supone que algunos directores realicen películas más próximas a la realidad, desde una actitud más crítica.

En el caso español, no podemos hablar de autores neorrealistas puros, sino más bien de directores que, contagiados de esa nueva forma de mirar que acota distancias entre el cine y la realidad, realizaron películas enmarcadas en el denominado "realismo social": Luís García Berlanga y Juan Antonio Bardem, principalmente, pero también Luís Buñuel, Ladislao Vadja, Fernando Fernán Gómez, Marco Ferreri, Carlos Saura y la olvidada Ana Mariscal. En algunas de ellas interviene además el guionista Rafael Azcona.

\subsection{El cartel cinematográfico durante el "realismo social" español}

Después de la guerra civil, el cartel español atraviesa un momento complicado, puesto que muchos de los cartelistas se encuentran en el exilio. No obstante, el diseño gráfico cinematográfico alcanza un gran desarrollo, principalmente en la tipología de programas de mano. Algunos de los cartelistas que se inician en estos años como Jano y MAC, tendrán cierta repercusión en la cartelería cinematográfica, llegando a realizar trabajos muy interesantes. Sin embargo, la tónica general será una cartelería mediocre, que se extiende hasta los años setenta (Sánchez López, 1997).

Así, al igual que no podemos hablar de directores españoles que cultiven exclusivamente el neorrealismo, después del estudio comparado realizado, no hemos encontrado en los carteles pertenecientes al "realismo social" español una estética diferenciada y propia. Como características generales del cartel de cine de este periodo (hasta finales de los sesenta del siglo XX), destacamos:

- Una abundancia de gamas cromáticas fuertes (colores chillones) 
- Una predominante representación en el cartel de los protagonistas de la película (provenientes del star-system español y, generalmente, a partir de una fotografía)

- Una pequeña escenificación de las acciones argumentales y/o temáticas.

- La fuente de inspiración y el máximo referente de los cartelistas se encuentra siempre en la propia película.

Cuando se produce alguna innovación respecto a ese modelo tan encorsetado, es consecuencia de la labor aislada de algunos cartelistas. Como resultado del análisis realizado, hemos seleccionado los siguientes autores: Josep Renau, Jano y Mac.

\subsubsection{Jano}

Su verdadero nombre era Francisco Fernández Zarza, pero tomó el seudónimo "Jano" del nombre del personaje central (un pintor bohemio) de un serial para el comic que dibujó durante los años 40.

Resultó el más polivalente de los cartelistas cinematográficos españoles. A él se deben más de 5000 carteles, que salieron de su estudio de la calle Bordadores de Madrid, donde llegó a recibir encargos de 20 distribuidoras simultáneamente. Jano fue cartelista oficial de la mayoría de las distribuidoras cinematográficas españolas, como Hispamex, Procines, Chamartín, Filmayer o Mercurio Films.

Además, fue uno de los mejores retratistas del star-system español y norteamericano, y en ocasiones, tuvo problemas con la censura franquista. En especial con el cartel "Surcos" (Nieves Conde, 1952), pues según declaraciones del propio Jano, el censor ordenó su secuestro aduciendo que el mensaje no iba a ser comprendido por el público español.

Su calidad como ilustrador, dibujante y caricaturista es indiscutible. Ninguna técnica o estilo tuvieron secretos para él. Su firma aparece en carteles pertenecientes al denominado "realismo social" español. Son destacables por su creatividad e innovación artística los realizados para las películas, además de "Surcos", "Cómicos" de Juan Antonio Bardem y “Bienvenido Mr Marshall”, de Luís García Berlanga.

Jano se aparta del estricto modelo ya mencionado y pone al servicio de los encargos una gran versatilidad que da como resultado la creación de unos carteles diferentes a la mayoría. Nuestras observaciones, resultado del análisis de contenido efectuado, se ven corroboradas por las declaraciones del propio autor:

Los distribuidores siempre me han exigido dibujar los rostros de los actores y actrices dentro de un diseño realista, convencional, chapado a la antigua, y yo siempre he querido hacer otra cosa, como esos carteles que se hacen en los países del Este. (Mensaje y Medios, 1990) 


\subsubsection{Mac}

Macario Gómez Quipus, junto con Jano ostenta el liderazgo de lo que se ha venido a llamar "la vieja escuela". Como decíamos anteriormente, empezó a trabajar en la década de los cuarenta y realizó más de 6.000 reclamos para el cine (incluyendo distintas tipologías).

Observamos en su obra un empleo mínimo de los elementos temáticos (cuando se lo permitían las distribuidoras), así como una rotulación que facilita la visión a larga distancia. Para Mac es importante aproximar el reclamo publicitario al cartel:

[...] el cartel tiene que ser una mancha de color. ¡Pinta lo que quieras! Pero el cartel tiene que entrar por los ojos. A cincuenta metros tienes que darte cuenta de lo que el cartel significa y que, al mismo tiempo, te dé la idea de lo que puede ser la película (Moya, 1983).

Según el cartelista, contó con más libertad creativa en los carteles que realizó para las multinacionales americanas que en los encargos españoles. No obstante, observamos que pese a las limitaciones impuestas por los distribuidores nacionales, Mac logró realizar trabajos de una gran creatividad, que incluso, llamaron la atención fuera de nuestras fronteras y que se acabaron empleando en las campañas internacionales.

Además de las características previamente señaladas, Mac incidió en el elemento pictórico $\mathrm{y}$, aunque tomaba como referente a las películas, a partir de ellas solía desarrollar sus propias ideas y efectuar trabajos que destacan por su originalidad y creatividad, respecto al modelo de cartel cinematográfico generalizado en estas décadas. Un caso paradigmático es el cartel que realizó para el film "El cochecito", de Marco Ferreri.

\subsubsection{Renau}

El cartelista Josep Renau, inició su actividad como cartelista de cine en Valencia a finales de los años 20, aunque supera ampliamente ese ámbito temporal y geográfico con su actividad en Méjico durante los años 40 y 50. La relación de Renau con el cartel de cine español fue corta pero muy significativa:

Su aparición trastocó gran parte de las técnicas y pensamientos plásticos habituales: excelente concepción compositiva entre la figura y el fondo, tratamiento colorista del espacio mediante tintas planas, y sobre todo, la frescura y fuerza geométrica de su dibujo, de regusto cubista y excelente técnica aerográfica (Sánchez López, 1997).

El cartelista mostraba un gran interés en recuperar a los viejos maestros de la pintura 
española (Velázquez en especial) y además, aplicar nuevos métodos de reproducción gráfica. También se interesó por las "artes" de la publicidad moderna.

Atendió con especial cuidado el tratamiento del color en cada cartel, incluso hasta la reducción de los motivos al blanco y negro. También realizaba variaciones sobre el esquema narrativo tradicional del cartel:

[...] se hace evidente que donde Renau podía experimentar- nuevos recursos técnicos, de color, grafismo, fotografía- experimentaba, y donde no podía, también lo hacía, en la medida en que la ironía puede ser condición de verdad, como afirma Barthes (Selma, 1996)

Nosotros destacamos por su originalidad compositiva el cartel que realiza para la película "Ensayo de un crimen", de Luís Buñuel.

\subsubsection{Los humoristas}

Dos casos destacables y excepcionales de humoristas que reciben encargos para el cine del "realismo social" español son Manuel Summers y Mingote. Su principal aportación fue incorporar (a través de la metáfora visual) un contenido crítico a la imagen tradicional, empleando el recurso del humor:

Con la dictadura del general Franco, la excepcional situación española propició la formación de una serie de humoristas e ilustradores, verdaderos maestros en el arte de la metáfora [...] colaboraron muy activamente en la formulación del nuevo grafismo hispano, no sólo con sus constantes colaboraciones en publicidad sino, sobre todo, por su papel de <<iniciadores>> en la incorporación- a través de la metáfora visual- de la carga crítica e ideológica a la imagen de consumo tradicional" (Satué, 1988).

En el cartel cinematográfico español contamos con dos extraordinarios ejemplos: el trabajo realizado por Summers para anunciar "Plácido", de Luís Berlanga y el efectuado por Mingote para la película “El Pisito”, de Marco Ferreri.

Ambos carteles rompen con el modelo generalizado, al mismo tiempo que logran retratar la España profunda, desde el enfoque del contenido, y risible, como resultado de la aplicación del humor en la composición del anuncio.

\section{CONCLUSIONES}

Las conclusiones alcanzadas, que se detallan a continuación, verifican la hipótesis de partida:

1. En el periodo analizado con la parte generalista de la muestra (desde los 
orígenes del cartel cinematográfico español hasta la década de los sesenta del siglo XX), los carteles repetían el mismo modelo de diseño, exceptuando algunos casos en la década de los veinte.

2. Los cartelistas estaban atados por rígidas normas de las distribuidoras cinematográficas que les exigían seguir un determinado modelo en sus carteles.

3. Las características de este modelo son:

- Una abundancia de gamas cromáticas fuertes (colores chillones)

- Una predominante representación en el cartel de los protagonistas de la película (provenientes del star-system español y, generalmente, a partir de una fotografía previamente seleccionada por la productora)

- También una pequeña escenificación de las acciones argumentales y/o temáticas.

- La fuente de inspiración y el único referente de los cartelistas tenían que encontrarlo en la propia película.

4. No existe un modelo de cartel para el cine español de "realismo social", puesto que no se han observado diferencias significativas entre el modelo cartel de ese estilo cinematográfico y el cartel de cine en general.

5. Cuando se producen innovaciones, no muchas, que se alejan del modelo tradicional, éstas son resultado de la iniciativa personal de los cartelistas españoles.

6. Como cartelistas destacables, por la labor creativa que despliegan en el cartel del cine del "realismo social" español, destacamos a Jano, Mac, Renau, principalmente, y en menor medida a los humoristas Mingote y Summers.

\section{REFERENCIAS}

Adam, Jean-Michel y Bonmhomme, Marc (2000): La argumentación publicitaria: retórica del elogio y de la persuasión. Cátedra. Madrid.

Baena Palma, Francisco (1996): “Creadores y entorno", en Cine de Papel. El cartel de cine en España. Ayuntamiento de Zaragoza. Zaragoza.

Barnicoat, John (1976): Los carteles. Su historia y lenguaje. Gustavo Gili. Barcelona.

Cervera, Elena e Iriarte, Ana (Coord.) (2004): Carteles de cine de 1915 a 1930. Filmoteca Española. Madrid.

García Fernández, Ma Soledad (1985): Arte y Publicidad en 100 años del cartel español, publicidad comercial 1875-1975. Centro Cultural Conde Duque. Madrid. 
Gubern, Román (1982): Historia del Cine. Lumen. Barcelona.

Gutiérrez Espada, Luis (1998): El cartel Art Nouveau. DRAC. Madrid.

Fernández Mellado, Rebeca (2007): El cartel de cine español de posguerra (1939-1945), disponible a texto completo en Cuadernos de Documentación Multimedia. Madrid. http://multidoc.rediris.es/cdm/viewarticle.php?id=57

Sánchez López, Roberto (1997): El cartel de cine. Arte y publicidad. Prensas Universitarias de Zaragoza, Zaragoza.

Satué, Enric (1998): El diseño gráfico desde los orígenes hasta nuestros días. Alianza. Madrid.

Selma, José Vicente (1996): "Renau: ironía y experimentación" en Cine de Papel. El cartel de cine en España. Ayuntamiento de Zaragoza. Zaragoza.

Tranche, Rafael (1996): "Pintar el aura", en Cine de Papel. El cartel de cine en España. Ayuntamiento de Zaragoza. Zaragoza.

Moya, César (1983): "Entrevista con Macario Gómez", en Dirigido por... n 100 de Enero de 1983.

Tosantos, Carlos Ma (1990): "Fulgor y muerte del cartel cinematográfico", en Mensaje y Medios, no 19 de Octubre de 1990.

\section{Tamara Bueno Doral}

Profesora e investigadora en el Departamento de Comunicación Audiovisual y Publicidad II. Además de impartir las asignaturas Historia del cine e Historia del cartel publicitario, es autora de diversas publicaciones que versan sobre comunicación y derechos humanos, análisis de los estereotipos presentes en los mensajes persuasivos y cuestiones de género en el audiovisual contemporáneo.

\section{Noelia García Castillo}

Licenciada en Publicidad y Relaciones Públicas por la Universidad Complutense de Madrid e Investigadora del Ministerio de Educación y Ciencia (FPU) en dicha universidad. Actualmente trabaja en el Departamento de Comunicación Audiovisual y Publicidad II mientras realiza su tesis doctoral. Sus investigaciones se centran en la representación de la diferencia en los medios de comunicación y en los estudios de género. 